\title{
Hydrogeochemical processes controlling water composition in the Salar de Atacama: A modelling approach
}

\author{
C. Poblete-GonZÁleZ ${ }^{1 *}$, F. ÁlvareZ-AMAdo ${ }^{1,2}$, L. $^{2}$ \\ GODFREY ${ }^{3}$ \\ ${ }^{1}$ Earth Science Department, Universidad de Concepción, \\ Concepción, Chile $(*$ correspondence: \\ campoblete@udec.cl) \\ ${ }^{2}$ Millennium Nucleus for Metal Tracing Along Subduction, \\ FCFM, Universidad de Chile, Santiago, Chile. \\ ${ }^{3}$ Department of Earth and Planetary Sciences, Rutgers \\ University, U.S.A.
}

The Salar de Atacama is a giant salt pan developed under the extremely dry conditions of the Atacama Desert in northern Chile. This basin lies between the Domeyko Range which consists of igneous rocks and clastic, carbonate and evaporite sedimentary rocks, and the Western Cordillera which is comprised of voluminous andesitic to rhyolitic ignimbrites, with minor volcanic rocks.

Although natural water sources of the region have been thoroughly studied in terms of their geochemistry and conventional isotopic composition, there are few works that use a modelling approach of hydrochemical processes taking place in the basin.

The study area focuses on the northern part of the Salar the Atacama. We model different processes that could determine the geochemical water composition, such as geothermal water mixing, evaporation and fluid-rock interaction. Hydrogeochemical modelling was carried out through PHREEQC software. Resulting simulations were then compared to geochemical and isotopic data measured in natural waters.

Geothermal waters show a limited interaction with meteoric waters, resulting in a mixture from 5 to $8 \%$. This dilution of thermal water replicates the major elemental composition of Vilama and San Pedro surficial streams.

A high percentage of water evaporation from an initial surface stream, of at least $73 \%$, is needed in the simulations to replicate the solute concentrations of groundwater. This would indicate that a combination of both evaporation and cold rock - water reaction processes are involved in the evolution of groundwater. In particular, evaporite and ignimbrite lithologies contribute to the chemical composition of waters within the Salar de Atacama basin. Our results suggest that the different processes modeled here, are controlling the hydrogeochemistry of the natural waters. 